Pacific Journal of Mathematics

SIMILARITIES INVOLVING NORMAL OPERATORS ON 


\title{
SIMILARITIES INVOLVING NORMAL OPERATORS ON HILBERT SPACE
}

\author{
MARY R. EMBRY
}

The primary purpose of this note is to exhibit a proof and several corollaries of the following theorem concerning continuous linear operators on a complex Hilbert space $X$.

Theorem 1. If $H$ and $K$ are commuting normal operators and $A H=K A$, where 0 is not in the numerical range of $A$, then $H=K$.

In the entire paper $A, E, H$ and $K$ represent continuous linear operators on $X, A^{*}$ is the adjoint of $A, W(A)$ is the numerical range of $A$ and $\sigma(A)$ is the spectrum of $A$. The terms self-adjoint, normal and unitary are used in the standard fashion. $A$ is quasinormal if and only if $A$ commutes with $A^{*} A$. A unitary operator is called cramped if and only if its spectrum is contained in an arc of the unit circle with central angle less than $\pi$.

In $\S 1$ a proof of Theorem 1 will be given, as well as several corollaries. In $\S 2$ corollaries of Theorem 1 , which are valid if either $0 \notin W(A)$ or $\sigma(A) \cap \sigma(-A)=\varnothing$, are presented.

1. A proof of Theorem 1. Let $h$ and $k$ be the spectral resolutions of $H$ and $K$ respectively. Since $A H=K A, A h(\alpha)=k(\alpha) A$ for each complex Borel set $\alpha$ by [10]. This last equation together with the fact that $h(\alpha)$ and $k(\alpha)$ are commuting projections implies that

(1) $p(\alpha)^{*} A p(\alpha)=q(\alpha)^{*} A q(\alpha)=0$ for each Borel set $\alpha$, where

$$
\begin{aligned}
& p(\alpha)=(I-h(\alpha)) A h(\alpha) \\
& q(\alpha)=h(\alpha) A(I-h(\alpha)) .
\end{aligned}
$$

( $I$ denotes the identity operator on $X$.) Since $0 \notin W(A)$, equation (1) implies that $p(\alpha)=q(\alpha)=0$. Thus by (2) $A h(\alpha)=h(\alpha) A$ for each Borel set $\alpha$ and consequently, $A H=H A$. Finally, $H A=K A$ and since $0 \notin W(A), H=K$.

The following two examples show that if $H$ and $K$ are normal and $A H=K A$, then $H$ and $K$ may differ if $0 \in W(A)$ or if $H$ and $K$ do not commute, even if $A$ is unitary.

EXAMPLE 1. If

$$
K=\left(\begin{array}{ll}
1 & 0 \\
0 & 2
\end{array}\right), A=\left(\begin{array}{ll}
0 & 1 \\
1 & 0
\end{array}\right), \text { and } H=\left(\begin{array}{ll}
2 & 0 \\
0 & 1
\end{array}\right),
$$


then $H$ and $K$ are normal, commute and $A H=K A$, but $H \neq K$.

EXAMPLE 2. If

$$
K=\left(\begin{array}{ll}
1 & 1 \\
1 & 2
\end{array}\right), A=\left(\begin{array}{ll}
1 & 0 \\
0 & i
\end{array}\right), \text { and } H=\left(\begin{array}{rr}
1 & i \\
-i & 2
\end{array}\right),
$$

then $H$ and $K$ are normal, $A H=K A$ and $0 \notin W(A)$, but $H \neq K$.

Corollary 1. [5]. If $A A^{*}$ and $A^{*} A$ commute and $0 \notin W(A)$, then $A$ is normal.

Proof. Let $H=A^{*} A, K=A A^{*}$ and note that $A H=K A$, so that Theorem 1 is applicable.

The technique used in the proof of Theorem 1 is essentially the same as that used in [5] to prove a slightly stronger version of Corollary 1.

CoROllary 2. If $0 \notin W(A)$ and there exist real numbers $r$ and $s$ such that $r^{2}+s^{2} \neq 0$ and $A$ commutes with $r A A^{*}+s A^{*} A$, then $A$ is normal.

Proof. In this case $A A^{*}$ commutes with $A^{*} A$ and Corollary 1 may be applied.

Several special cases of Corollary 2 are known. If $A$ is quasinormal and $0 \notin W(A)$, then $A$ is normal [4]. If $A$ commutes with $A A^{*}-A^{*} A$, then $A$ is normal [11]. This last follows from Corollary 2 by applying the corollary to $A-z I$ (which commutes with

$$
\left.(A-z I)(A-z I)^{*}-(A-z I)^{*}(A-z I)\right)
$$

for $z \notin W(A)$.

In [12] C. R. Putnam proved a stronger version of the next corollary.

Corollary 3. [12]. If $A^{2}$ is normal and $0 \notin W(A)$, then $A$ is normal.

Proof. By [7], [8], or [10] $A^{*} A^{2}=A^{2} A^{*}$ if $A^{2}$ is normal. Thus $A A^{*}$ and $A^{*} A$ must commute and Corollary 1 is applicable.

We note that the condition $0 \notin \sigma(A)$ is not sufficiently strong to guarantee that $A$ is normal when $A^{2}$ is normal. (For example take any nonnormal square root of the identity operator $I$.) However, we recall that if $A^{2}$ is normal and $\sigma(A) \cap \sigma(-A)=\varnothing$, then $A$ is 
normal [6]. This suggests that perhaps Theorem 1 and Corollary 1 remain valid if the hypothesis $\sigma(A) \cap \sigma(-A)=\varnothing$ is substituted for the hypothesis $0 \notin W(A)$. Example 3 provides a counterexample to this proposition.

Example 3. Let $A=\left(\begin{array}{lll}0 & 2 & 0 \\ 0 & 0 & 1 \\ 3 & 0 & 0\end{array}\right)$. Direct computation shows that $A A^{*}$ and $A^{*} A$ commute and differ from one another. Moreover, $\sigma(A) \cap \sigma(-A)=\varnothing$ since $z \in \sigma(A)$ if and only if $z^{3}=6$. If we take $H=A^{*} A$ and $K=A A^{*}$, then $A H=K A, H$ and $K$ are normal and commute, but $H \neq K$.

2. The condition $0 \notin W(A)$ or $\sigma(A) \cap \sigma(-A)=\varnothing$. Although the two conditions $0 \notin W(A)$ and $\sigma(A) \cap \sigma(-A)=\varnothing$ do not yield the same results, as seen by Example 3, several corollaries of Theorem 1 remain valid if the hypothesis $0 \notin W(A)$ is replaced by

$$
\sigma(A) \cap \sigma(-A)=\varnothing \text {. }
$$

In the remainder of the paper we let $D$ be the set of all operators $A$ for which either $0 \notin W(A)$ or $\sigma(A) \cap \sigma(-A)=\varnothing$.

Because of the importance of Theorem 2 in the following corollaries, we restate it here.

Theorem 2. [6]. If $\sigma(A) \cap \sigma(-A)=\varnothing$, then $A$ and $A^{2}$ commute with exactly the same operators.

Corollary 4. If $A \in D$ and $A E=-E A$, where either $A$ or $E$ is normal, then $E=0$.

Proof. If $\sigma(A) \cap \sigma(-A)=\varnothing$, then by Theorem $2 A E=E A$ since $A^{2} E=E A^{2}$. Therefore $E=0$. Assume now that $0 \notin W(A)$. If $E$ is normal, we apply Theorem 1 and have $E=-E$ or $E=0$. If $A$ is normal, then $A^{*} E=-E A^{*}$ by [10] and thus $A\left(E-E^{*}\right)=$ $-\left(E-E^{*}\right) A$. Since $E-E^{*}$ is normal, $E=E^{*}$ by Theorem 1 . Consequently, $E$ is normal and a second application of Theorem 1 yields $E=-E=0$.

Corollary 5. If $A$ is a normal element of $D$, then $A$ and $A^{2}$ commute with exactly the same operators.

Proof. Assume that $A^{2} E=E A^{2}$ and let $H=A E-E A$. Then $A H=-H A$ and by Corollary $4, H=0$.

Corollary 6. If $A E=E^{*} A$ and $A E^{*}=E A$, where $A \in D$, then 
$E$ is self-adjoint.

Proof. Under these hypotheses $A\left(E-E^{*}\right)=-\left(E-E^{*}\right) A$ and Corollary 4 can be applied to the normal operator $E-E^{*}$, resulting in $E=E^{*}$.

Corollary 7. If $A E=E^{*} A$, where $A \in D$ and either $A$ is unitary or $E$ is normal, then $E$ is self-adjoint.

Proof. If $E$ is normal, then $A E^{*}=E A$ by [10]; if $A$ is unitary, then $E A^{*}=A^{*} E^{*}$ and consequently, $A E^{*}=E A$. Thus in either case Corollary 6 may be applied.

Corollary 7 includes a slight improvement of a result of J.P. Williams. In [13] Williams proved that $\sigma(E)$ is real if $A E=E^{*} A$, where 0 is not in the closure of $W(A)$. Thus if $E$ is normal, $E$ is self-adjoint. In particular, Williams noted that if $E$ is normal and $A E=E^{*} A$, where $A$ is a cramped unitary operator, then $E$ is selfadjoint. More generally, in [1] W. A. Beck and C. R. Putnam and in [2] S. K. Berberian proved this same result without the hypothesis that $A$ is normal. Finally, in [9] C. A. McCarthy obtained a generalization from which it follows that if $A E=E^{*} A, A$ unitary and $\sigma(A) \cap \sigma(-A)=\varnothing$, then $E$ is self-adjoint. All of these results are included in Corollary 7.

For completeness we include the following special case of Theorem 1.

CoROLlaRY 8. If $H$ and $K$ are commuting normal operators and $H=A^{*} K A$, where $A$ is a cramped unitary operator, then $H=$ $K$.

Proof. $A H=K A$ since $A$ is unitary and $0 \notin W(A)$ since $A$ is cramped [3]. Thus Theorem 1 is applicable.

In Corollary 9, we have a result similar to that of Theorem 1. The hypothesis that $H$ and $K$ commute is replaced by $A^{*} H=K A^{*}$.

Corollary 9. Let $A H=K A$ and $A^{*} H=K A^{*}$, where $A \in D$. If $A$ is unitary or $H$ and $K$ are normal, then $H=K$.

Proof. If $H$ and $K$ are normal, we also have $A H^{*}=K^{*} A$ and $A^{*} H^{*}=K^{*} A^{*}$ by [10]; if $A$ is unitary, these equations also hold since $H A^{*}=A^{*} K$ and $H A=A K$. If we now define 


$$
\mathscr{A}=\left(\begin{array}{ll}
A & 0 \\
0 & A
\end{array}\right) \text { and } \mathscr{E}=\left(\begin{array}{lr}
0 & H \\
K^{*} & 0
\end{array}\right) \text {, }
$$

direct computation shows that $\mathscr{A} \mathscr{E}=\mathscr{E} * \mathscr{A}$ and $\mathscr{A} \mathscr{E}^{*}=\mathscr{E} \mathscr{A}$. Since $W(\mathscr{A})=W(A)$ and $\sigma(\mathscr{A})=\sigma(A)$, Corollary 6 may be applied to show $\mathscr{E}=\mathscr{E} *$. Thus $H=K$.

A rather curious result can be obtained by using the technique of proof in Corollary 9. Note that $\mathscr{E}$ (as defined in the proof of Corollary 9) is normal if and only if $H H^{*}=K K^{*}$ and $H^{*} H=K^{*} K$. But by Corollary 7 if $\mathscr{E}$ is normal, $\mathscr{A} \in D$ and $\mathscr{A} \mathscr{E}=\mathscr{E}^{*} \mathscr{A}$, then $\mathscr{E}$ is self-adjoint and $H=K$. Thus we have:

COROLLARY 10. Let $H$ and $K$ be operators such that $H H^{*}=K K^{*}$ and $H^{*} H=K^{*} K$. If there exists an element $A$ of $D$ such that $A H=K A$ and $A^{*} H=K A^{*}$, then $H=K$.

To Professor S. K. Berberian, I express my sincere gratitude for suggesting Corollaries 9 and 10, the method of proof used in these corollaries, and the reference to C. A. McCarthy's paper. I also wish to thank Professor P. R. Halmos for his helpful comments on this paper.

\section{REFERENCES}

1. W. A. Beck and C. R. Putnam, A note on normal operators and their adjoints, J. London Math. Soc. 31 (1956), 213-216.

2. S. K. Berberian, A note on operators unitarily equivalent to their adjoints, J. London Math. Soc. 37 (1962), 403-404.

3. - The numerical range of a normal operator, Duke Math. J. 31 (1964), 479-483.

4. A. Brown, On a class of operators, Proc. Amer. Math. Soc. 4 (1953), 723-728.

5. M. R. Embry, Conditions implying normality in Hilbert space, Pacific. J. Math. 18 (1966), 457-460.

6. $-n^{\text {th }}$ roots of operators, Proc. Amer. Math. Soc. 19 (1968), 63-68.

7. B. Fuglede, A commutativity theorem for normal operators, Proc. Nat. Acad. Sci. 36 (1950), 35-40.

8. P. R. Halmos, Commutativity and spectral properties of normal operators, Acta Szeged 12 (1950), 153-156.

9. C. A. McCarthy, On a theorem of Beck and Putnam, J. London Math. Soc. 39 (1964), 288-290.

10. C. R. Putnam, On normal operators in Hilbert space, Amer. J. Math. 73 (1951), $357-362$.

11. - On the spectra of commutators, Proc. Amer. Math. Soc. 5 (1954), 929931.

12. - On square roots of normal operaiors, Proc. Amer. Math. Soc. 8 (1957) 768-769. 
13. J. P. Williams, Operators similar to their adjoints, Proc. Amer. Math. Soc. 20. (1969), 121-123.

Received January 20, 1970.

The University of North Carolina at Charlotte 


\section{PACIFIC JOURNAL OF MATHEMATICS}

\section{EDITORS}

\author{
H. SAMELSON \\ Stanford University \\ Stanford, California 94305

\section{Richard Pierce} \\ University of Washington \\ Seattle, Washington 98105
}

J. DugundJI

Department of Mathematics

University of Southern California

Los Angeles, California 90007

RichaRd ARENS

University of California

Los Angeles, California 90024

\section{ASSOCIATE EDITORS}
E. F. BECKENBACH
B. H. NeUMANN
F. WOLE
K. YoshidA

\section{SUPPORTING INSTITUTIONS}

\author{
UNIVERSITY OF BRITISH COLUMBIA \\ CALIFORNIA INSTITUTE OF TECHNOLOGY \\ UNIVERSITY OF CALIFORNIA \\ MONTANA STATE UNIVERSITY \\ UNIVERSITY OF NEVADA \\ NEW MEXICO STATE UNIVERSITY \\ OREGON STATE UNIVERSITY \\ UNIVERSITY OF OREGON \\ OSAKA UNIVERSITY \\ UNIVERSITY OF SOUTHERN CALIFORNIA
}

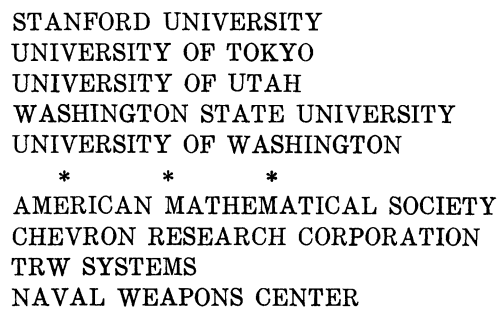

The Supporting Institutions listed above contribute to the cost of publication of this Journal, but they are not owners or publishers and have no responsibility for its content or policies.

Mathematical papers intended for publication in the Pacific Journal of Mathematics should be in typed form or offset-reproduced, (not dittoed), double spaced with large margins. Underline Greek letters in red, German in green, and script in blue. The first paragraph or two must be capable of being used separately as a synopsis of the entire paper. The editorial "we" must not be used in the synopsis, and items of the bibliography should not be cited there unless absolutely necessary, in which case they must be identified by author and Journal, rather than by item number. Manuscripts, in duplicate if possible, may be sent to any one of the four editors. Please classify according to the scheme of Math. Rev. Index to Vol. 39. All other communications to the editors should be addressed to the managing editor, Richard Arens, University of California, Los Angeles, California, 90024.

50 reprints are provided free for each article; additional copies may be obtained at cost in multiples of 50 .

The Pacific Journal of Mathematics is published monthly. Effective with Volume 16 the price per volume (3 numbers) is $\$ 8.00$; single issues, $\$ 3.00$. Special price for current issues to individual faculty members of supporting institutions and to individual members of the American Mathematical Society: $\$ 4.00$ per volume; single issues $\$ 1.50$. Back numbers are available.

Subscriptions, orders for back numbers, and changes of address should be sent to Pacific Journal of Mathematics, 103 Highland Boulevard, Berkeley, California, 94708.

PUBLISHED BY PACIFIC JOURNAL OF MATHEMATICS, A NON-PROFIT CORPORATION

Printed at Kokusai Bunken Insatsusha (International Academic Printing Co., Ltd.), 7-17, Fuj̣imi 2-chome, Chiyoda-ku, Tokyo, Japan. 


\section{Pacific Journal of Mathematics}

\section{Vol. 35, No. $2 \quad$ October, 1970}

Valentin Danilovich Belousov and Palaniappan L. Kannappan, Generalized Bol functional equation .................................... 259

Charles Morgan Biles, Gelfand and Wallman-type compactifications ........... 267

Louis Harvey Blake, A generalization of martingales and two consequent convergence theorems .................................... 279

Dennis K. Burke, On p-spaces and $w \Delta$-spaces..................... 285

John Ben Butler, Jr., Almost smooth perturbations of self-adjoint operators . . . . . . 297

Michael James Cambern, Isomorphisms of $C_{0}(Y)$ onto $C(X) \ldots \ldots \ldots \ldots \ldots . \ldots 307$

David Edwin Cook, A conditionally compact point set with noncompact closure ... 313

Timothy Edwin Cramer, Countable Boolean algebras as subalgebras and homomorphs .........................................

John R. Edwards and Stanley G. Wayment, A v-integral representation for linear operators on spaces of continuous functions with values in topological vector spaces.............................................

Mary Rodriguez Embry, Similarities involving normal operators on Hilbert

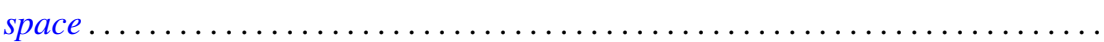

Lynn Harry Erbe, Oscillation theorems for second order linear differential

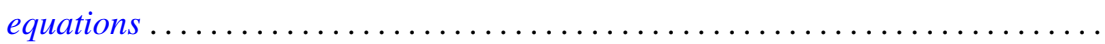

William James Firey, Local behaviour of area functions of convex bodies .......... Joe Wayne Fisher, The primary decomposition theory for modules ..............

Gerald Seymour Garfinkel, Generic splitting algebras for Pic ..................

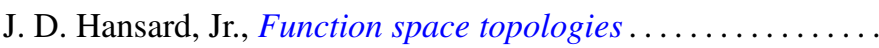

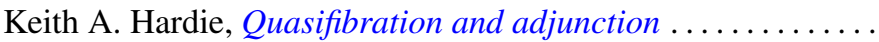

G. Hochschild, Coverings of pro-affine algebraic groups ...........

Gerald L. Itzkowitz, On nets of contractive maps in uniform spaces ..

381

389

399

417

Melven Robert Krom and Myren Laurance Krom, Groups with free nonabelian subgroups....................................

James Robert Kuttler, Upper and lower bounds for eigenvalues by finite differences ......................................

Dany Leviatan, A new approach to representation theory for convolution transforms . . .

Richard Beech Mansfield, Perfect subsets of definable sets of real numbers ...

Brenda MacGibbon, A necessary and sufficient condition for the embedding of a

Lindelof space in a Hausdorff $\mathscr{H} \sigma$ space ..................

David G. Mead and B. D. McLemore, Ritt's question on the Wronskian ....

Edward Yoshio Mikami, Focal points in a control problem .....

Paul G. Miller, Characterizing the distributions of three independent n-dimensional random variables, $X_{1}, X_{2}, X_{3}$, having analytic characteristic functions by the joint distribution of $\left(X_{1}+X_{3}, X_{2}+X_{3}\right)$. . .

P. Rosenthal, On the Bergman integral operator for an elliptic partial differential equation with a singular coefficient....

Douglas B. Smith, On the number of finitely generated $O$-group 